\title{
Improving the quality of paediatric care in peripheral hospitals in developing countries
}

\section{T Duke, G Tamburlini, The Paediatric Quality Care Group}

\section{A coordinated and collaborative approach is required}

$\mathrm{R}$ ecent observational evidence suggests there is considerable scope for improving the quality of hospital care for severely ill children in many developing countries. ${ }^{1}$ In a study of 21 hospitals in Asia and Africa that evaluated the management of 131 children, more than half were under treated or inappropriately treated with antibiotics, fluids, feeding, or oxygen. Inadequate triage and assessment, poor treatment, and insufficient monitoring may adversely affect the outcome of a significant proportion of hospitalised children, and result in unnecessary suffering or avoidable death for many children each year. In some other settings overhospitalisation, over-diagnosis of severe illness, and over-medication has adverse consequences for health outcomes and in wasted health expenditure. ${ }^{2-4}$ Until recently little attention was paid to these issues; the reasons are several. Firstly, because many more children in low income countries die before reaching any hospital for want of more basic interventions, such as measles vaccine or oral rehydration solution, and the legitimate concern that promoting hospitals may detract from primary level or community based care. Secondly, confronting potentially avoidable deaths or suffering in children is upsetting, to communities, to hospitals, and to health workers who struggle to provide the highest level of care they can. Furthermore, in most countries academic thought and energy has been predominantly directed towards clinical problems seen in tertiary university hospitals, with inadequate consideration of the health system problems in peripheral hospitals, which are often understaffed, poorly equipped and maintained, and with little or no ongoing staff education. Also, until recently there has been little evidence that outcomes could be improved without very major investment in staffing and technology.

While there are examples of inequitable and inefficient resource allocation where tertiary hospitals have consumed disproportionate resources and starved primary health care, good quality first referral level (or district hospital) care is crucial for reducing child mortality and for a credible and efficient primary health care system. Implementation of integrated management of childhood illness (IMCI) guidelines implies referral of up to $20 \%$ of patients in most settings. These children are the most severely ill and those at highest risk of death. It is important that case management in hospitals follows diagnostic criteria and treatment guidelines that are consistent with the IMCI outpatient or local primary care guidelines, otherwise the credibility of such guidelines may be undermined and the strategies ultimately abandoned.

"Good quality district hospital care is crucial for reducing child mortality"

There is now some evidence for improvement in outcomes for hospitalised children through support for health workers, structured clinical care, and better use of existing resources, rather than major financial or technological investment. Recent work from Brazil and Malawi suggests that emergency triage, assessment and treatment guidelines can be used by nurses to identify children needing high priority treatment. ${ }^{56}$ Case management of severe malnutrition $^{7-9}$ and pneumonia, ${ }^{10}$ and neonatal care $^{11}$ can be substantially improved with better ward organisation, clinical guidelines, active staff participation, and limited additional resources.

Components of quality improvement strategies are standards, assessment tools, participation, and driving forces. Standards of care must be specific to the level of the health facility and the needs of the country, reflect an appropriate balance between resources used for curative and public health, and emphasise low cost simple technology options and drugs. In collaboration with paediatricians worldwide, the World Health Organisation (WHO) has developed guidelines for clinical management of children with severe illnesses at hospitals of first referral. ${ }^{12}$ These require only limited laboratory services but essential drugs for the care of seriously ill children. Some countries have their own long traditions of treatment protocols for common illnesses that act as standards of care. ${ }^{13}$

Structured assessments of quality of care in hospitals have taken place in several countries, including Peru, Brazil, Angola, and several newly independent states of Central Asia. ${ }^{2-414} 15$ These have included assessment of infrastructure, drugs, equipment, human resources, laboratory services, records, and observed quality of clinical care. Assessment models combine self reported data by hospitals, and experienced observers working with local paediatricians and health workers. The aim is to describe the characteristics of hospitals and the health service, their major problems and strengths, and the resources available. By targeting a few crucial areas that are limiting steps in quality of clinical care, strategies for improvement can be defined..$^{15}$ As part of informing health policy these hospital assessments provide feedback for clinicians and prompt discussion about ideas for change where it is necessary. Such assessments may be an important entry point in planning improvements to hospital clinical care, ${ }^{15}$ but it is important that they are linked to long term implementation strategies and not exercises in data gathering. Identifying solutions to high priority problems, and highlighting key structural or political problems that require longer term input, are both important if quality improvement is to be sustained, and if clinicians are to have confidence in the process. It is important also that hospital based interventions do not take precedence when there are major deficiencies in public health such as unsafe drinking water, poor immunisation rates, or a lack of primary care strategy. The issues are not confined to developing countries. Transition countries and developed countries need to improve the quality of care as well, although priorities and limiting factors may be substantially different.

\footnotetext{
"Documented experience with paediatric mortality and morbidity audit is scarce"
}

Development of audit and critical incident monitoring may be an initial step when quality improvement is being generated within small hospitals where staff have limited time and resources. Although there is a strong tradition of effective perinatal and surgical auditing from developed and developing countries, documented experience with paediatric mortality and morbidity audit is 
scarce. A problem solving approach to paediatric audit, based on comparison of actual management against standards and evidence based clinical guidelines can have positive benefits. If such audits are conducted in a sensitive way they can serve the purpose of team building and be a focus of continuing education. ${ }^{16}$

The success of hospital assessments and internally driven quality improvement processes depend on having sufficient resources to effect and sustain gradual changes, and local staff having ownership over the process. ${ }^{17}$ In Peru a maternal and neonatal quality improvement programme has built a wide variety of improvements to clinical practice and education around self identification of problems by health facility clinical teams. The problems identified relate to drug and equipment supplies, lack of standardised care or training for specific diseases, and issues of client satisfaction. The clinical teams attempt to identify and solve problems by themselves. In only about $20 \%$ of cases this is not possible, and they then request help from the local level authorities, referral hospitals, or the central ministries of health. Health centres participating in this project report an increased demand for care, and a reduction in case fatality among mothers delivering, compared with non-participating health centres. ${ }^{18}$

There is a need for more research on strategies that work and those that do not, and the levels of support required. The evidence base to WHO hospital guidelines $^{12}$ should be carefully documented if we are to encourage widespread usage and incorporation into teaching programmes. In addition the evidence for and against treatments for common illnesses that are given in some countries but not recommended need to be documented. This will be necessary if effective local adaptations, which merge current treatments and WHO guidelines are to occur. Research is needed to field test the effectiveness of a range of approaches to quality improvement (external assessment, internal audit, etc).

Standards, assessment tools, and evidence are essential, but not alone sufficient for the process to succeed. There is a financial cost to running a service that is good enough to prevent avoidable morbidity and deaths. In many settings much can be done with very little if one builds on existing human resources; health workers generally embrace initiatives to improve care as long as such initiatives are appropriately supported, adding value and a sense of fulfilment to their work. In some settings there will be substantial cost shifting from inefficient practices, and a better quality clinical service may be provided for not much more than current costs. Rationalisation of over-hospitalisation and overmedication using standardised clinical guidelines would free up considerable funds in some health systems. However, in most lower income countries resources are so limited and manpower so over-extended that problems highlighted by external or internal assessments will be demoralising to health workers if sufficient financial, technical, and human resources are not made available to affect change. In the chain where good data inform effective implementation the links are made up of on-ground motivation, funding, and political will.

Quality improvement should be integrated into a variety of clinical and management initiatives. The overall approach should not be limited to paediatric medical care, as there is evidence of a need for improvement in perinatal care, ${ }^{19} 20$ preand post-surgical care and anaesthesia management, ${ }^{21-23}$ and general hospital practices, ${ }^{23}$ to further lower hospital case fatality rates in less developed countries.

\section{"Principles of quality improvement will need to be integrated into training"}

For these issues to be part of the health culture, principles of quality improvement will need to be integrated into undergraduate and postgraduate training, and incorporated into regional hospitals providing second referral level and tertiary teaching hospital care. Larger hospitals are where medical students, interns, and nurses get their value systems about good medical practice, and set patterns for a lifetime of work. For effective local adaptation of clinical guidelines, evidence based capacity must be developed among paediatricians in lower income countries. This may be done by partnerships with Western universities that offer appropriate evidence based medicine and public health training, with the assistance of international partners who could provide training fellowships.

Basic principles of quality improvement need also to be incorporated into training for child health nurses, clinical assistants, health extension officers, and other paramedical health workers, as these clinicians often work in the least supported and resourced environments. In such settings empowerment of and support for nurses to make management decisions will require skills not previously taught in undergraduate training, and a cultural shift in roles, hierarchies, and expectations for both nurses and doctors.

There is a need for international and local organisations to support these issues. A worldwide effort for improving quality of paediatric hospital care requires collaboration from WHO, other international agencies, and nongovernment organisations with large international coverage, and major donors such as the World Bank. Initially support may help define strategies that are effective and acceptable in a variety of resource poor settings. There are pivotal roles for paediatricians, paediatric nurses, and their professional organisations to play; the International Paediatric Association has the potential to encourage this work at national and regional levels. Effective partnerships between the IPA and WHO have the potential for extensive coverage, offering technical support to clinical paediatricians and to those in management positions within Ministries of Health. National paediatric societies can collaborate with health authorities in deciding what approaches are appropriate locally, adapting standards of care to local resources and circumstances, training and supervision, assessing clinical care, providing feedback and support, and evaluating outcomes. Countries without formal paediatric societies or paediatricians need the most support. There are also roles for collaborative involvement of non-government organisations; however, the processes decided on must be owned internally, within health ministries, paediatric societies, and health facilities. The equity of approaches within the overall health care system, and what are appropriate for an individual country's circumstances, will require careful consideration, and can only be decided at a local level.

\section{SUMMARY}

The quality of medical and nursing care provided in peripheral hospitals in developing countries has an impact on the health and lives of millions of children each year. With recent evidence that such care is poor in many places there is a need for a serious coordinated approach. Improvements in triage, diagnosis, treatment guidelines, monitoring, and follow up may reduce case fatality and iatrogenic complications. These can be seen as public health as well as clinical problems, and demand approaches that can be brought to large scale. Structured hospital assessments might provide an entry point for deciding priorities for improvement, and the effective implementation and integration of evidence based standardised clinical guidelines will be important for many countries. Simple ways to evaluate the quality of clinical care and strategies for making improvements need to be included in undergraduate medical, nursing, and paramedical curricula and in postgraduate training. Research is needed to document the evidence behind standard treatment guidelines and investigate the acceptability and effectiveness of different quality development approaches in smaller rural and remote 
health systems. Developing skills in evidence based practice among paediatricians in lower income countries will be important for local adaptation and longer term sustainability of quality improvement strategies. Academic thought needs to be applied to addressing the problems of poorly functioning district hospitals; the problems in these hospitals should not be seen as out of sight and out of mind. A coordinated and collaborative approach is required that may involve ministries of health, national paediatric associations, the $\mathrm{WHO}$, the International Paediatric Association, Western and developing country university departments, and non-government organisations.

\section{ACKNOWLEDGEMENT}

Many people contributed ideas to this paper The Paediatric Quality Care Group is an email discussion group that has included: Ganapati Bhat, Harry Campbell, Andrew Clark, Simona Di Mario, Mike English, Angelika Krug, Claudio Lanata, Michael Gracey, Lena Grahnquist, Elmarie Malek, Sue Nicholson, Steve Rogers, Jacques Schmitz, TL Soo, David Southall, Abner Targoola, and Martin Weber. Many of the ideas in the paper were discussed at an International Workshop at the University of Pretoria, South Africa in November 2001

Arch Dis Child 2003;88:563-565

\section{Authors' affiliations}

T Duke, Centre for International Child Health, Department of Paediatrics, University of Melbourne, Royal Children's Hospital, Parkville, 3052, Victoria, Australia

G Tamburlini, Unit for Health Services Research and International Health, Institute for Child Health IRCCS "Burlo Garofolo", Trieste, Italy
Correspondence to: Dr T Duke, Centre for International Child Health, Department of Paediatrics, University of Melbourne, Royal Children's Hospital, Parkville, 3052, Victoria Australia; trevor.duke@rch.org.au

\section{REFERENCES}

Nolan T, Angos P, Cunha AJLA, et al. Quality of hospital care for seriously ill children in less developed countries. Lancet 2001;357:106-10.

2 Duke T. Assessment of quality of paediatric hospital-based care: Kazakhstan. Copenhagen: WHO Regional Office for Europe, Child and Adolescent Health and Development, 2002.

3 Tamburlini G. Assessment of quality of paediatric hospital-based care: Moldova. Copenhagen: WHO Regional Office for Europe, Child and Adolescent Health and Development, 2002.

4 Weber M. Assessment of quality of paediatric hospital-based care: Russia. Copenhagen: WHO Regional Office for Europe, Child and Adolescent Health and Development, 2002.

5 Tamburlini G, Di Mario SD, Maggi RS, et al. Evaluation of guidelines for emergency triage assessment and treatment in developing countries. Arch Dis Child 1999;81:478-82.

6 Robertson MA, Molyneux EM. Triage in the developing world-can it be done? Arch Dis Child 2001:85:208-13.

7 Ahmed T, Ali M, Ullah MM, et al. Mortality in severely malnourished children with diarrhoea and use of a standardised management protocol. Lance 2001;353:1912-22.

8 Wilkinson D, Scrace M, Boyd N. Reduction in in-hospital mortality of children with malnutrition. J Trop Pediatr 1996;42:1 14-15.

9 Puoane T, Sanders D, Chopra M, et al. Evaluating the clinical management of severely malnourished children - a study of two rural district hospitals. S Afr Med J 2001;91:137-41.

10 Duke T, Frank D, Mgone J. Hypoxaemia in children with severe pneumonia in Papua New Guinea. Int J TB Lung Dis 2000;5:511-19.

11 Duke T, Willie L, Mgone JM. The effect of introduction of minimal standards of neonatal care on in-hospital mortality. PNG Med J 2000;43:127-36.
12 World Health Organisation. Management of the child with a serious infection or severe malnutrition: guidelines for care at the first-referral level in developing countries. Geneva: WHO, 2001.

13 PNG Department of Health. Standard treatment for common illnesses of children in Papua New Guinea: a manual for nurses, health extension officers and doctors. Port Moresby: PNG Department of Health, 2000.

14 Tamburlini G, Di Mario S, Vilarim JN, et al. Assessment of quality of care in paediatric wards: experience in Brazil. Proceedings of the 32nd IUALTD Conference, Paris, 1-4 November 2001

15 Pivetta S, Bernadino L, Correia M, et al. Assessing and improving quality of paediatric hospital care in Angola. Medico e Bambino 2002;21:603-4

16 Duke T, Michael A, Mgone J, et al. Etiology of child mortality in Goroka, Papua New Guinea: a prospective two-year study. Bull World Health Organ 2002;80: 16-25.

17 Mancey-Jones M, Brugha RF. Using perinatal audit to promote change: a review. Health Policy Plan $2001 ; 12: 183-92$

18 World Health Organisation. The Maternal and Child Training Program-PCMI. Informal consultation on possible approaches to improving quality of paediatric care in small hospitals in developing countries. Geneva: Department of Child and Adolescent Health and Development, World Health Organisation, 2001:22-8.

19 Pattinson RC, Makin JD, Shaw A, et al. The value of incorporating avoidable factors into perinatal audits. $S$ Afr Med 1995:85: 145-7

20 Salinas AM, Coria I, Reyes $\mathrm{H}$, et al. Effect of quality of care on preventable perinatal mortality. Int J Qual Health Care 1997:9:93-9.

21 Inbasegaran K, Kandasami P, Sivalingam N. A 2-year audit of perioperative mortality in Malysian hospitals. Med J Malaysia 1998;53:321-4.

22 McKenzie AG. Mortality associated with anaesthesia at Zimbabwean teaching hospitals. S Afr Med J 1996;86:338-42.

23 Garcia-Martin M, Lardelli-Claret $P$, Bueno-Cavanillas A, et al. Proportion of hospital deaths associated with adverse events. J Clin Epidemiol 1997;50:1319-26. 


\section{PostScript}

\section{LETTERS}

If you have a burning desire to respond to a paper published in $A D C$ or $F \vartheta N$, why not make use of our "rapid response" option?

Log on to our website (www.archdischild. com), find the paper that interests you, click on "full text" and send your response by email by clicking on "submit a response"

Providing it isn't libellous or obscene, it will be posted within seven days. You can retrieve it by clicking on "read eLetters" on our homepage.

The editors will decide, as before, whether to also publish it in a future paper issue.

\section{Oral clodronate as treatment of osteogenesis imperfecta}

The benefits of treatment with intravenous pamidronate in osteogenesis imperfecta (OI) have recently been reported. ${ }^{1-3}$ These include reduced bone resorption, increased bone density, and improved clinical outcomes as judged by apparently lower fracture rates. We would like to report a single case of OI treated by the orally administered bisphosphonate, clodronate, with good effect.

A boy, whose mother was affected with clinically diagnosed type 1 osteogenesis imperfecta, was referred to our unit aged 131/2 with a recent onset of severe back pain that had required hospital admission. He appeared of normal stature with blue sclerae and was able to walk independently. He had sustained four previous limb fractures; lateral radiographs of the thoracic and lumbar spine confirmed three vertebral wedge fractures. He was $158.9 \mathrm{~cm}$ tall (10th centile) and weighed $49 \mathrm{~kg}$ (25th centile). Lumbar spine bone mineral density scanning by dual $x$ ray absorpiometry (DXA, Hologic QDR-1000, Hologic, Bedford, MA) revealed a BMD of $0.398 \mathrm{~g} / \mathrm{cm}^{2}$ (Z score -5.22 , comparing his value to the average young man). Fasting urinary hydroxyproline/creatinine ratio, an index of bone resorption, was 96.6.

With informed parental consent for "off label" usage, he was commenced on oral sodium clodronate (Bonefos, Leiras Oy, Turku, Finland) at a dose of $400 \mathrm{mg}$ daily. Dietary intake of calcium and vitamin D was above the estimated average requirement and supplementation was not given. Subsequent BMD scanning after one year of therapy showed an improvement of bone density by $7.8 \%$ to $0.468 \mathrm{~g} / \mathrm{cm}^{2}$ with a consequent increase in the BMD Z score to -5.09 .

Treatment with clodronate was continued for five years, during which time he did not sustain any new low trauma fractures. By the end of treatment, his BMD was 0.552 and his $\mathrm{Z}$ score had improved from -5.22 at first referral to -4.59 . The fasting urinary hydroxyproline:creatinine ratio was decreased by $86 \%$ compared to baseline ( $13.6 v 96.6$ ). Clodronate was discontinued for eight months; during this time his BMD remained stable but the Z score showed a small decline. His height at that stage lay on the 50th centile $(176 \mathrm{~cm})$ and his weight on the 10th $(58 \mathrm{~kg})$. The BMD remained considerably below the normal value and clodronate was recommenced at a dose of $800 \mathrm{mg}$ daily.

Eight years after initial referral, his bone mineral density had increased by $60.6 \%$ to $0.613 \mathrm{~g} / \mathrm{cm}^{2}$ (Z score -4.16 ). To compensate for the expected increase in bone size, the bone mineral adjusted density (BMAD) was computed $\left(\mathrm{BMD}_{\mathrm{LL}-\mathrm{L} / \mathrm{A}} / \mathrm{square}\right.$ root of area $\left.\mathrm{a}_{\mathrm{LI}-\mathrm{L} 4}\right)$ and showed an improvement of $24.6 \%$ in BMAD over the duration of therapy. Clodronate was discontinued when the patient was aged 22. He had reached a height of $177.4 \mathrm{~cm}$ and a weight of $60.8 \mathrm{~kg}$, and the spine BMD Z score was -3.92 . He had suffered no atraumatic fractures since commencing oral clodronate.

The rationale in using bisphosphonates for osteogenesis imperfecta is the inhibition of osteoclastic bone resorption leading to increased bone density and a potentially lower risk of fracture. This young man exhibited a good response to therapy with oral clodronate, suffering no adverse reactions. The increase in height of $18 \mathrm{~cm}$ over eight years, moving him from the 10th to 50th centile, suggests that his growth was not impaired by therapy. ${ }^{4}$ Many studies have shown that clodronate does not impair mineralisation. We are unable to determine the contribution of remodelling of vertebral fractures to his height gain.

A limitation of this report is that pubertal status was not documented at presentation. However, the increases in lumbar spine density are in excess of the expected average rates in growing children $(3-6 \%$ per year and $14-16 \%$ during puberty). ${ }^{1}$ The increase was also observed following adjustment for bone growth by BMAD and $\mathrm{Z}$ scores relating the measured BMD to age matched controls. The $\mathrm{Z}$ score $(-5.22$ to -3.92$)$ improvement during therapy was not dissimilar to that reported with pamidronate ${ }^{1}$ in younger children.

We agree that there is increasing evidence of a role for bisphosphonate therapy as part of the multidisciplinary management of osteogenesis imperfecta. Oral clodronate in our patient appeared to elicit a similar response to that of cyclical intravenous pamidronate, suggesting that orally administered bisphosphonates may be of value in the management of this disease.

R U Ashford, A Dey, K Kayan, E V McCloskey, J A Kanis Sheffield Metabolic Bone Unit, Sheffield, UK robert.ashford@virgin.net

\section{References}

1 Glorieux FH, Bishop NJ, Plotkin $\mathrm{H}$, et al. Cyclic administration of pamidronate in children with severe osteogenesis imperfecta. N Engl J Med 1998;339:947-52.

2 Åström E, Söderhäll S. Beneficial effects of long term intravenous bisphosphonate treatment of osteogenesis imperfecta. Arch Dis Child 2002;86:356-64

3 Baneriee I, Shortland GJ, Evans WD, et al. Osteogenesis imperfecta and intravenous pamidronate. Arch Dis Child 2002;87:562.

4 Nagant de Deuxchaisnes C,

Rombouts-Lindemans C, Haux JP, et al. Diphosphonates and inhibition of bone mineralisation. Lancet 1982;2:607-8.

\section{Serum prolactin in coeliac schoolchildren}

Literature published suggests that in children with coeliac disease (CD) serum prolactin concentrations are increased, and correlate with the grade of mucosal atrophy. It has been proposed that prolactin is a possible marker of disease activity. ${ }^{1}$ Other studies, however, have failed to show this correlation in children with CD. ${ }^{2}$

We studied prolactin levels in children with $\mathrm{CD}$, and the correlation with the severity of intestinal mucosal atrophy.

We used samples from a serum bank obtained during a mass screening for $\mathrm{CD}$ in Sardinian schoolchildren, using both antiendomysial antibodies and antigliadin antibodies as screening tests, as previously described. ${ }^{3}$ The sample included 20 children with $\mathrm{CD}$ on a gluten containing diet ( 16 girls, 4 boys, mean age 12.9 years, range $11.5-14.4$ years) and 40 sex and age matched normal children ( 32 girls, 8 boys, mean age 13.0 years, range 11.2-14.8 years). All subjects were euthyroid. Prolactin was assayed in duplicate using a commercial immunoradiometric method; results were analysed by analysis of covariance.

Data are expressed as mean (SE). Prolactin levels were $4.62(2.1) \mathrm{ng} / \mathrm{ml}$ in patients with $\mathrm{CD}$ and 5.90 (2.6) ng/ml in controls (no statistically significant difference). No correlation was found between prolactin concentrations and the degree of intestinal damage (Marsh criteria).

Our study did not confirm the increased prolactin concentrations in children with $\mathrm{CD}$ reported by Reifen and colleagues. ${ }^{.}$Our population differed somewhat in that there was a higher mean age (12.9 $\vee 11.3$ years), a narrower age range ( $11.5-14.4 v 5-18$ years), and a different girl:boy ratio $(4: 1 \quad \vee \quad 1: 1)$. Furthermore, our study included three potential coeliacs (subjects with antiendomysium antibodies positivity but normal intestinal biopsy $^{4}$ ) and 11 asymptomatic coeliac children. The hypothesis that the normal prolactin values observed in our study may be due at least in part to the different clinical characteristics of the population studied is plausible, but its validation requires a specifically designed study. 


\section{Acknowledgement}

Study performed using grant 34/39-2000 (Coeliac disease and iodine-deficiency diseases) to GD from Regione Sardegna.

G Fanciulli, P A Tomasi, G Delitala Dipartimento-Struttura Clinica Medica-Patologia Speciale Medica, University of Sassari, Italy

A D'Appello, G Fanciulli Sr Divisione di Pediatria Ospedale Civile di Alghero, Italy

Correspondence to: $\operatorname{Dr} G$ Fanciulli, Dipartimento-Struttura Clinica Medica-Patologia Speciale Medica, University of Sassari, Viale S. Pietro 8, 07100 Sassari, Italy; gfanciu@uniss.i

\section{References}

1 Reifen R, Buskila D, Maislos M, et al. Serum prolactin in coeliac disease: a marker for disease activity. Arch Dis Child 1997;77:155-7

2 Theintz GE, Nussle D, Cox J, et al. Prolactin and the gut: a controversy. J Pediatr Gastroenterol Nutr 1984:3:523-8.

3 Catassi C, Fanciulli G, D'Appello AR, et al. Antiendomysium versus antigliadin antibodies in screening the general population for coeliac disease. Scand J Gastroenterol 2000:35:732-6.

4 Ferguson A, Arranz E, O'Mahony S. Clinical and pathological spectrum of coeliac disease-active, silent, latent, potential. Gut 1993:34:150-1.

\section{BOOK REVIEWS}

\section{A Clinical Guide to Inherited Metabolic Diseases, 2nd edn}

Edited by JTR Clarke UK: Cambridge University Press, 2002, £29.95, pp 306. ISBN 0521890764

Dr Clarke's enthusiasm and erudition are evident on every page of this book, which is handily sized, and, wonder of wonders, costs only $£ 30$.

Most of the chapters are written with a clinically based approach, and the chapters on basic principles in understanding inherited metabolic disease, neonatal screening, hy poglycaemia, metabolic acidosis, storage diseases, and dysmorphism will be read with a sensation of increasing revelation by jus about any paediatrician, and those with a secure background in biochemistry and metabolic disease will pick up many nuggets of wisdom.

Why then, do I simply not recommend every paediatrician who sometimes deals with metabolic problems-and there must be few of us who do not-to rush out and buy a copy before such a gem either goes out of print or rises in price? My caveat is that this book's clinical approach coupled with its encyclopaedic coverage of some topics means that several chapters leave the non-expert mentally breathless, and this effect is made worse by the absence of the structural formulae of the molecules named; this may be of little moment to those with these formulae at their fingertips, but that excludes rather a lot of us. By contrast the metabolic sections of "Nelson" and "Forfar and Arniel" clearly benefit from their inclusion.

So, for those on a unit dealing with many patients with inborn errors of metabolism, this book is invaluable, but general and trainee paediatricians who think they can read this book from start to finish and become initiated into the mysteries of metabolic disease are likely to be overwhelmed.

If you can peruse this paperback at your local medical bookshop, do so; you may find it an answer to prayer, and anyway, at just under $£ 30$ it won't bankrupt anyone.

R A F Bell

\section{Eating Problems in Children: Information for Parents.}

Edited by C Fox, C Joughin. London: Gaskell 2002, £10.00, pp 621. ISBN 1901242862

How commonly do we encounter the following scenario?

A desperately anxious mother at last convinces her GP that she needs to see a paediatrician because her normally growing toddler is eating nothing. The paediatrician wonders why his time is being wasted, and "reassures" the mother that there is nothing to worry about. Needless to say the anxiety persists with, no doubt, damaging consequences. As a profession, we handle these cases poorly. With $30 \%$ of preschool children suffering from mild to moderate eating problems, we need a better way to address these issues.

The Royal College of Psychiatrists has produced this small book for parents that should prove helpful, not only to parents but also to paediatricians and other health professionals. It provides information about the epidemiology of eating problems, and gives a useful classification, categorising eating difficulties into nine types, including persistence of eating inappropriate texture of food for age, food refusal, restrictive eating and selective eating. This allows the parent or professional to come to a more specific "diagnosis", and also a sense of the anticipated course these difficulties are likely to take. In particular, it provides clear pointers for those conditions that are indicative of significant emotional or psychiatric conditions.

Giving clear indications to the parent as to when to worry is helpful, as it is likely to encourage a sense of proportion to the anxiety accompanying the more common eating difficulties. The book goes on to provide specific and sensible advice about the practical management for each of the different types of eating difficulty.

At the end of the day, one is left with the finding that for most parents, not surprisingly, reassurance is what is required. I felt, however, that this book could help us proffer the advice in a more substantive form than we do at present, and can give us an approach that is likely to help diffuse the anxiety which contributes to the perpetuation of stressful mealtimes. I suspect the book will prove to be of most value to health visitors, but selected reading could be of use to the paediatrician

This book is therefore of value for a problem that presents so frequently to the general paediatrician, but I must admit to some reservations. It could have been better written, and in particular was rather unnecessarily repetitive. It certainly would have benefitted from paediatric review-I wondered who or what a community practitioner was, and gulped when I saw growth hormone mentioned in the section of treatment for restrictive eating! It was rather more concerning that children with disabilities got an occasional mention,

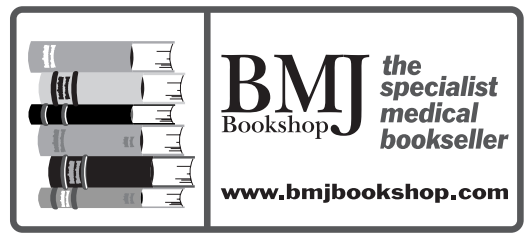

implying that they merited the same sort of approach. It surely would have been better to emphasise that they require a different sort of understanding and input. But, despite these concerns, the book should prove useful as it provides a systematic approach to the child with eating difficulties, and some clear, sensible practical advice to guide the parent in handling the problem.

M Rudolf

\section{Childhood Headache}

Edited by I Abu-Arafeh. UK: Cambridge University Press, 2002, £45, pp 184. ISBN 1 898683263

Headaches in children are a common problem- $70 \%$ of school children have headaches at least once a year, with 25\% suffering from recurrent headaches. This book is part of the Clinics in Developmental Medicine series and provides a comprehensive overview of the subject. The book is divided into clear chapters, which makes it easy to dip into. It includes interesting sections on pain perception in children and neonates, as well as good epidemiology section. Throughout the book there are summary tables of recently published studies. In the later chapters there are case histories, including parental descriptions, which break up the occasionally slightly long winded text. There is an extensive list of references at the end of each chapter.

I found the chapters on migraine enlightening, especially the theories on pathophysiology of migraine. The diagnostic criteria for migraine are easy to read and clear. There is an excellent overview on the psychological treatment of headaches, regardless of diagnostic type. Again, the evidence is summarised in clear tables. There is a practical section on managing abdominal migraine. Causes of headaches are divided into separate chapters for specific and rare causes, which was helpful when I used the text when on call.

The final chapter talks about setting up a headache clinic, including a discussion on diagnostic tests. There is a headache questionnaire for parents, which I would find very helpful. There is also advice on the role of the multidisciplinary team in management.

This book would be a valuable addition to a general paediatric department, both in outpatients and for reference when on call.

A Morjaria

\section{CORRECTIONS}

In the article by Nixon et al (Arch Dis Child 2002;87:306-11), Dr Claire Wainwright should have been included as an author. Dr Wainwright's contribution was the establishment of the methodology and early patient recruitment and testing. Dr Wainwright moved from The Royal Children's Hospital at the end of 1997, and was funded by The Royal 
Children's Hospital Foundation, Brisbane and the Cystic Fibrosis Research Inc, Queensland. The authors apologise for the omission.

The authors of the letter "Childhood SARS in Singapore" in the August issue (Arch Dis Child 2003;88:742) were written incorrectly. The authors names should be P Van Bever, C P P Hia, S C Quek.
In the acknowledgements for the leading article by Duke et al (Arch Dis Child 2003;88:563-5), Dr Diana Silimperi should have been acknowledged as part of the Paediatric Quality Care Group. The authors apologise for the error.

An error occurred in the paper by Riordan M, Rylance G, Berry $\mathrm{K}$ in the November issue.
(Poisoning in children 1: General management. Arch Dis Child 2002;87:393-6). In table 2 , pupillary constriction associated with signs of increased sympathetic nervous system activity should read as mild pupillary dilation. Anticholinergic agents are likely to produce a more marked dilation. The authors apologise for the error.

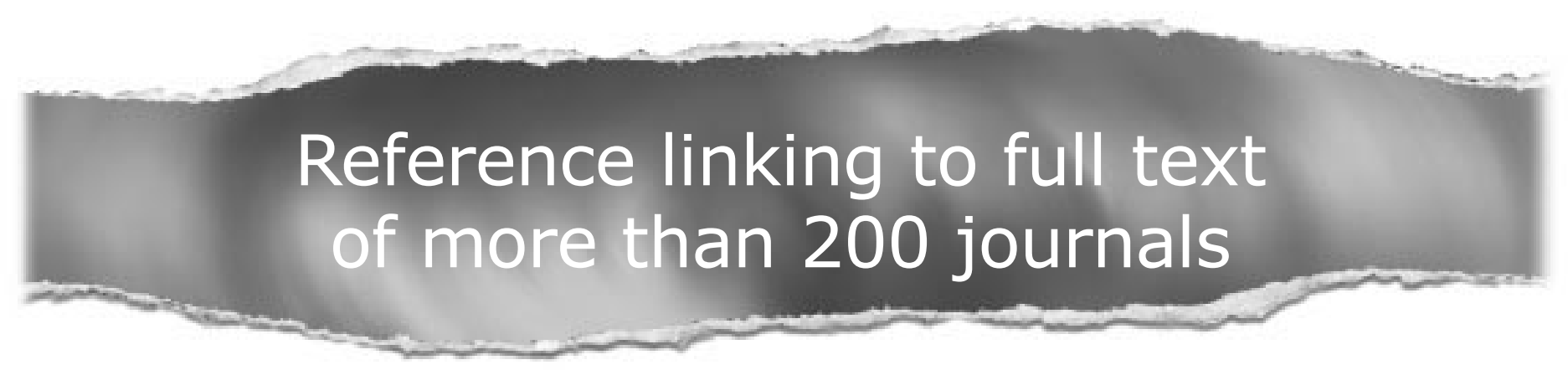

Toll free links

You can access the FULL TEXT of articles cited in Archives of Disease in Childhood online if the citation is to one of the more than 200 journals hosted by HighWire (http://highwire.stanford.edu) without a subscription to that journal. There are also direct links from references to the Medline abstract for other titles.

www.archdischild.com 